\title{
Male reproductive success in Pseudotsuga menziesii (Mirb.) Franco: the effects of spatial structure and flowering characteristics
}

\author{
JAROSŁAW BURCZYK*† \& DANIEL PRAT $\ddagger$ \\ †Department of Biology and Environmental Protection, Pedagogical University, Chodkiewicza 30, PL 85-064 \\ Bydgoszcz 1, Poland and $¥$ Laboratoire INRA-ENGREF de Sciences Forestières, Unité de Génétique des Populations \\ d'Arbres Forestiers, ENGREF, 14, rue Girardet, F-54042 Nancy Cedex, France
}

\begin{abstract}
Reproductive patterns and effective pollen dispersal were investigated in a Douglas-fir (Pseudotsuga menziesii (Mirb.) Franco) clonal seed orchard using 11 isozyme loci as genetic markers. Progenies from 94 mother trees were analysed by the mixed-mating and the neighbourhood models and outcrossing rates were estimated as 0.96 and 0.97 , respectively. The proportion of offspring resulting from pollination by males located outside the neighbourhood of each mother tree ( $30 \mathrm{~m}$ in radius) was estimated as 0.54 , with $\approx 43$ per cent of matings resulting from outcrossing with nearby males (within neighbourhoods). The effects of distance and direction of individual males from mother trees, pollen fecundity and phenological synchronization were all significant in determining outcross mating patterns within neighbourhoods. Generally, male reproductive success increased with proximity and phenology overlap with mother tree and pollen fecundity. The effect of different factors influencing male reproductive success varied among the three groups of mother trees divided according to the time of female receptivity (early, intermediate and late). Phenology was important in the early and intermediate groups, whereas fecundity was important in the intermediate and late phenology groups. Both distance and directionality effects were significant in the early and late classes. The directionality effect could be partially explained by the wind patterns existing during the pollination period. The mean effective number of males mating with each female within neighbourhoods was 10.95 (49.31 per cent of males within neighbourhoods).
\end{abstract}

Keywords: mating system, neighbourhood model, pollen dispersal, Pseudotsuga menziesii, reproductive success.

\section{Introduction}

The mating system plays a central role in determining the genetic structure of plants. Patterns of pollen dispersal, gene flow between populations and differential reproductive success influence the levels of inbreeding, as well as effective population size and distribution of genetic diversity between and within populations. In addition to their importance to population genetics theory, mating patterns are also of great practical value in agriculture and forestry (Adams \& Birkes, 1991; Snow \& Lewis, 1993). Variation in male fertility is common among plant

\section{${ }^{*}$ Correspondence. E-mail: burczyk@wsp.bydgoszcz.pl}

§Present address: INRA, Station d'Amélioration des Arbres Forestiers, F-45160 Ardon, France. species and it is expected that several factors, including distance, fecundity and flowering phenology, may affect individual reproductive success and patterns of pollen dispersal (Broyles \& Wyatt, 1991; Adams et al., 1992b; Devlin et al., 1992; Snow \& Lewis, 1993; Burczyk et al., 1996). For theoretical and practical reasons it is important to identify these factors and the best way to achieve this is the application of genetic estimation techniques using selectively neutral genetic markers (Smouse \& Meagher, 1994). Apparently, if an effect of a possible factor influencing reproductive success is to be calculated from individual fertilities, paternity methods are not very suitable for determining its significance if exclusion probabilities are not very high (Devlin et al., 1988; Adams et al., 1992b). Otherwise, the parameter esti- 
mates based on these methods can be substantially biased (Adams, 1992). Estimation of individual fertilities may also be difficult if many potential fathers exist, unless a large number of progeny is examined (Roeder et al., 1989).

If specific mating system parameters are of interest, a natural approach is to use probability models designed to account for observed frequencies of multilocus genotypes in pollen gametes of offspring samples, and then estimate these parameters using either least squares (LS) or maximum likelihood (ML) statistical methods. This mating model approach was employed to investigate male fertilities based on LS procedures in a white spruce (Picea glauca (Moench) Voss) seed orchard (Schoen \& Stewart, 1986). A more general model for estimating male fertilities in angiosperms using ML procedures was presented by Roeder et al. (1989). However, both methods assume that mating occurs only within populations. Adams \& Birkes (1989, 1991) proposed the neighbourhood model, which takes into account the possibility of mating with distant males located outside a local population, and is particularly useful for predominantly outcrossing, especially wind-pollinated species. Additionally, the neighbourhood model allows individual male reproductive success to be related to various factors that may influence it (Burczyk et al., 1996).

Seed orchards are artificial forest tree populations established to promote the production of genetically improved seeds used for reforestation purposes and they are important for breeding programs of several conifers. In order to attain expected genetic gains, several assumptions about mating patterns must be met. From this perspective, mating system studies in seed orchards are of particular interest (Adams et al., 1992a; Wheeler \& Jech, 1992). Coniferous clonal seed orchards have several features which make them very useful for investigations of male reproductive success (Adams et al., 1992a). Additionally, in conifers the pollen (paternal) contribution to each embryo can be determined based on codominant genetic markers by assaying the megagametophyte and the diploid embryo.

Selfing in conifers usually accounts for less than 10 per cent of seeds and a large proportion of fertilizations in seed orchards result from gene flow (contamination) from distant pollen sources (Muona, 1990; Adams \& Birkes, 1991; Savolainen, 1991). However, the information on the outcrossing patterns, including reproductive success and effective pollen dispersal within seed orchards, is rather limited (Wheeler et al., 1993). In this paper we demonstrate the application of the neighbourhood model to the progeny arrays in a Douglas-fir (Pseudotsuga menziesii (Mirb.) Franco) seed orchard using isozymes as genetic markers, and illustrate the effects of several factors (distance, direction, flowering fecundity and phenology) in determining mating success of individual males.

\section{Materials and methods}

The seed orchard studied was established in 1978 and laid out in Lavercantière in a broad-leaved forest area (near Cahors, France, $1^{\circ} 20^{\prime} \mathrm{E}, 44^{\circ} 37^{\prime} \mathrm{N}$ ). The orchard (14 ha in size) consists of 70 Douglasfir clones selected phenotypically by INRA (France) and Danish State Forestry for height growth, stem straightness and then wood density from a provenance trial established in Denmark. All trees included in the provenance experiment originated from the Darrington provenance in Washington State, U.S.A. Clonal ramets were planted at $8 \times 6 \mathrm{~m}$ spacing and randomly distributed in the orchard. At the time of sampling there were 1128 growing ramets. Flowering has taken place for several years. However, gibberellins $A_{4 / 7}$ treatment and girdling were practised on some trees in order to enhance flowering and seed production (Bonnet-Masimbert \& Webber, 1995). No Douglas-fir stands are located around the studied seed orchard.

Seeds were collected in autumn 1990 from one or two ramets of each clone. The progeny of 94 ramets (mother trees) growing at least $25 \mathrm{~m}$ inside the orchard borders were sampled. All mother trees (with their progeny) were divided into three groups of early-, intermediate- and late-flowering clones, according to the mean day of female receptivity (23, 36 and 35 ramets, respectively). The analyses of mating system were executed for each reproductive phenology class separately, as well as for the total population. For each ramet, about 10 seeds (pairs of megagametophyte and embryo tissues, 925 seeds in total) were analysed electrophoretically using standard procedures (Conkle et al., 1982) based on 11 gene loci: Aat-2, Est-1, Fdh, G6pdh, Glydh, Idh, Lap-1, Mdh-1, Mdh-3, 6Pgd and Sod. Enzyme systems were stained following various procedures (Conkle et al., 1982; Adams et al., 1990; Lewandowski \& Mejnartowicz, 1992). The multilocus genotypes of all 70 clones present in the orchard were also obtained.

The standard estimates of single- $\left(t_{\mathrm{s}}\right)$ and multilocus $\left(t_{\mathrm{m}}\right)$ outcrossing rates were calculated based on a mixed-mating model using the maximum likelihood procedures that were developed for conifers (Ritland \& El-Kassaby, 1985), after which the neigh- 
bourhood model was applied following Adams \& Birkes $(1989,1991)$. In this model it is assumed that pollen that successfully fertilizes viable embryos of a mother tree comes from three sources: self-fertilization (with probability $s$ ); outcrossing with trees growing outside an arbitrary specified area around a mother tree (with probability $m$; the area around a mother tree is the neighbourhood); and outcrossing with trees located within the neighbourhood (probability $1-m-s$ ), with relative mating success (i.e. fertility) of the $j$ th outcross male in the neighbourhood equal to $\phi_{j}$. In our analyses the neighbourhood size was set to be $30 \mathrm{~m}$ in radius, which already has been found to be sufficient in the case of seed orchards (Adams et al., 1992a). The probability of observing multilocus genotype $g_{i}$, among pollen gametes of offspring from a mother tree is:

$$
P\left(g_{i}\right)=s P\left(g_{i} \mid M\right)+(1-m-s) \sum_{j=1}^{r} \phi_{j}\left(g_{i} \mid F_{j}\right)+m P\left(g_{i} \mid B\right),
$$

where $P\left(g_{i} \mid M\right), P\left(g_{i} \mid B\right)$, and $P\left(g_{i} \mid F_{j}\right)$ are the transition probabilities (Devlin et al., 1988; Adams \& Birkes, 1991) that the pollen gamete with genotype $g_{i}$ is produced by the mother tree, by pollen sources outside the neighbourhood and by the $j$ th (out of $r$ ) outcross male in the neighbourhood, respectively. It is assumed that the mating success of each outcross male in the neighbourhood $\left(\phi_{j}\right)$ follows an exponential relationship (Adams \& Birkes, 1991; Burczyk et al., 1996). In this study we related male mating success to four factors:

$$
\phi_{\mathrm{j}}=\frac{e^{\beta d_{j}+\gamma f_{j}+\varphi p_{j}+\dot{\delta} \cos \left(\alpha_{0}-\alpha_{j}\right)}}{\sum_{k=1}^{r} e^{\beta d_{k}+\gamma f_{k}+\varphi p_{k}+\dot{\delta} \cos \left(\alpha_{0}-\alpha_{k}\right)}},
$$

where $d_{j}, f_{j}$ and $p_{j}$ indicate distance $(\mathrm{m})$ from the mother tree, fecundity and phenology scores (see below), respectively, and $\cos \left(\alpha_{0}-\alpha_{j}\right)$ is the angle cosine between the presumed prevailing direction of effective pollen dispersal and the location of the $j$ th male within a neighbourhood (Burczyk et al., 1996). The parameters $\beta, \gamma, \varphi$ and $\delta$ are the estimated parameters that describe the effects of the respective factors.

Mating system parameters included in various models were estimated by fitting the models to multilocus pollen gametic arrays in the offspring of individual mother trees using maximum likelihood (ML) methods (Rao, 1973; Roeder et al., 1989). This was carried out using the NEIGHBOR computer program (Burczyk et al., 1993). Details on statistical procedures have been reported elsewhere (Burczyk et al., 1996; documentation of NEIGHBOR program).

Given estimates of the mating system parameters, fertilities of individual males within a neighbourhood $\left(\phi_{j}\right)$ can be obtained from eqn (2) (Burczyk et $a l ., 1996)$. These fertilities were used to calculate the effective number of pollen parents in the neighbourhood siring offspring of an individual mother tree and the mean distance of effective pollen dispersal between mother trees and their outcross mates within neighbourhoods (Adams \& Birkes, 1989; Burczyk et al., 1996).

Observations of male flowering intensity and male and female flowering phenology were made in spring 1990 prior to the seed collection. For each clone, from two to 11 grafts (six on average) were investigated. For each graft one of four male fecundity scores $(0,1,2$ or 3$)$ was assigned, where 0 and 3 indicated the absence of and the greatest male flowering, respectively. Additionally, the timing of the start and end of male and female flowering was noticed for each ramet. Individual ramet data were used to obtain average clonal estimates. However, ramets with zero fecundity scores were excluded as potential fathers in the neighbourhood analyses. Phenology scores (eqn 2), indicating the degree of flowering overlap between a mother tree and potential outcross males in the neighbourhood were calculated using the NEIGHBOR program, following procedures originally developed by Adams and co-workers (Adams \& Birkes, 1989; documentation of NEIGHBOR program). The standard deviation of the flowering period, $\sigma$, for each clone was estimated according to Erickson \& Adams (1989). In the present study we assumed that 10 per cent and 90 per cent of reproductive strobili had shed pollen or become receptive to pollen when the start and end of flowering was observed. Thus $\sigma$ was estimated as: $\sigma=\left(x_{90}-x_{10}\right) / 2 z$, where $z=1.28$ (Snedecor \& Cochran, 1980).

Heterogeneity of mating system parameters was investigated by Fisher's heterogeneity $\chi_{\text {HET }}^{2}$ test (Rao, 1973). The significance of the null hypotheses, that $t=1$ and that $m=0$, was determined by analysing the limits of confidence intervals. The significance of other mating system parameters in the neighbourhood model $(s, \beta, \gamma, \varphi, \delta)$ was tested using the likelihood ratio test (Rao, 1973). Finally, in order to verify the validity of mating system estimations based on the neighbourhood model we calculated exclusion probabilities (EP) within each neighbourhood using an empirical approach (Roeder et al., 1989) following 5000 simulations. The 
EP is the probability of being able to exclude potential males on the basis of genetic incompatibility alone (Adams, 1992). High estimates of EP suggest high precision of mating system parameter estimates.

\section{Results}

Multilocus outcrossing rate $\left(t_{\mathrm{m}}\right)$ was estimated to be 0.963 for the total population, which means that only 3.7 per cent of embryos resulted from self-fertilization $(s=1-t)$ (Table 1$)$. The estimates of outcrossing did not vary among phenology classes, although the highest value was observed for the intermediate group. Single-locus outcrossing rates $\left(t_{\mathrm{s}}\right)$ varied considerably and were statistically heterogeneous across the studied loci for all groups except the intermediate class (data not shown). The mean values of single-locus outcrossing rates within groups were similar to the respective multilocus estimates. The multilocus estimate for the total population, as well as several single-locus estimates, were significantly different from unity $(t \neq 1$; Table 1$)$.

On average, there were $\approx 29$ grafts growing within the neighbourhoods of individual mother trees, although only 22.2 grafts produced male flowers and were considered as potential fathers. EP calculated for each neighbourhood ranged between 0.648 and 0.834 , with a mean of 0.756 , thus, on average, 16.8 of 22.2 males within the neighbourhoods could be excluded as potential fathers of a given offspring, based on genetic incompatibility. The mean standard error of EP estimates was 0.003 .

Selfing estimates were generally low (0.0160.042 ), although selfing was a significant factor in all groups except the early phenology class (Table 1 ). The proportion of successful pollen coming from outside of the neighbourhood was found to be 0.544 for the total population, and decreased from the early to the late phenology classes. Consequently, the proportion of outcrossing with local males (within the neighbourhood) increased from 0.307 in the early to 0.485 in the late phenology class. The total population accounted for 42.6 per cent of local outcross matings.

Generally, all factors expected to influence mating success of individual males (distance, fecundity, phenology and directionality) were significant in describing outcross mating patterns within the neighbourhood, although each factor affected the mating success to different degrees. The strongest effect was observed for the components related to flowering characteristics. Both fecundity and phenology were highly significant for the total population $(P<0.0001$; Table 2), but their importance changed among phenology classes. For the early group phenology but not fecundity was important, whereas the opposite situation occurred in the late group. Both factors were very important in the intermediate class. The differential influence of fecundity and

Table 1 Estimates of mating system parameters and the most likely directions of pollen influx within the neighbourhood, calculated for different phenology classes of Pseudotsuga menziesii from the mixed-mating and neighbourhood models (standard errors in parentheses)

\begin{tabular}{|c|c|c|c|c|}
\hline \multirow{2}{*}{$\begin{array}{l}\text { Mating system } \\
\text { parameter }\end{array}$} & \multicolumn{3}{|c|}{ Reproductive phenology class } & \multirow{2}{*}{$\begin{array}{c}\text { Total } \\
\text { population }\end{array}$} \\
\hline & Early & Intermediate & Late & \\
\hline \multicolumn{5}{|l|}{ Mixed-mating model } \\
\hline Outcrossing $\left(t_{\mathrm{m}}\right)$ & $\begin{array}{c}0.952 \\
(0.034)\end{array}$ & $\begin{array}{c}0.963 \\
(0.026)\end{array}$ & $\begin{array}{c}0.954 \\
(0.028)\end{array}$ & $\begin{array}{r}0.963^{\mathrm{a}} \\
(0.015)\end{array}$ \\
\hline \multicolumn{5}{|l|}{ Neighbourhood model } \\
\hline Selfing $(s)$ & $\begin{array}{c}0.0162 \\
(0.0153) \\
P=0.0643\end{array}$ & $\begin{array}{c}0.0419 \\
(0.0185) \\
P=0.0013\end{array}$ & $\begin{array}{c}0.0336 \\
(0.0195) \\
P=0.0283\end{array}$ & $\begin{array}{c}0.0299 \\
(0.0105) \\
P<0.0001\end{array}$ \\
\hline Background pollination $(m)$ & $\begin{array}{c}0.6766 \\
\quad(0.0807) \\
P<0.001\end{array}$ & $\begin{array}{c}0.5868 \\
(0.0609) \\
P<0.001\end{array}$ & $\begin{array}{c}0.4810 \\
\quad(0.0530) \\
P<0.001\end{array}$ & $\begin{array}{c}0.5440 \\
(0.0348) \\
P<0.001\end{array}$ \\
\hline $\begin{array}{l}\text { Local outcrossing } \\
(1-s-m)\end{array}$ & 0.3072 & 0.3713 & 0.4854 & 0.4261 \\
\hline
\end{tabular}

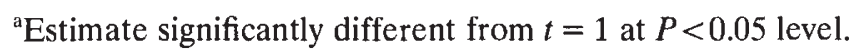


phenology may be clearly observed if relative mating success $\left(\phi_{j}\right)$ is plotted against the fecundity and phenology scores for different phenology classes (Fig. 1). In the intermediate class, generally, only males with the highest fecundity and the greatest flowering phenology overlap with mother trees could be successful in mating.

The distance and directionality effects were not significant in the intermediate group, but they were important in the early and the late phenology classes (Table 2). Distance was also significant for the total population. Although the mean physical distance between any mother tree and potential fathers within the neighbourhood was $\approx 20.5 \mathrm{~m}$, the mean distance of effective pollen dispersal varied among different phenology groups because of the variable distance effect $(\beta)$ and was calculated to be 14.75 ,
21.28 and $16.52 \mathrm{~m}$ for the early, intermediate and late classes, respectively (Table 2 ). The values, lower than the mean physical distances, indicate that mating occurs mainly between near-neighbours. The relationship between distance and relative mating success is presented in Fig. 2. Finally, only distance and fecundity effects were found to be significantly heterogeneous among phenology classes (Table 2).

The primary direction of effective pollen dispersal $\left(\alpha_{0}\right)$, which gave the best fit of the model (the greatest $\log$-likelihood), varied widely among phenology classes (Fig. 3). The estimates of $\alpha_{0}$ were found to be (in degrees from north) 172 (nearly south) for the early, 306 (nearly north-west) for the intermediate, and 358 (nearly north) for the late group (Table 2). The direction for the total population was estimated to be 353 (nearly north). However, a significant

Table 2 Estimates of parameters of outcross mating success within the neighbourhood calculated for different phenology classes of Pseudotsuga menziesii. The significance of individual estimates $(P)$ was calculated from the $\log$-likelihood ratio test $\left(N_{\mathrm{e}}\right.$, effective population size; $N_{\mathrm{e}} / N$, proportion of effective to actual population size; standard errors in parentheses)

\begin{tabular}{lcccc}
\hline $\begin{array}{l}\text { Parameters of } \\
\text { outcross mating }\end{array}$ success & \multicolumn{2}{c}{ Reproductive phenology class } & Total \\
\cline { 2 - 4 } & Early & Intermediate & Late & population \\
\hline Main parameters & & & & \\
Fecundity effect $(\gamma)^{\mathrm{a}}$ & 0.2635 & 3.0699 & 1.7454 & 1.7195 \\
& $(0.5092)$ & $(1.0283)$ & $(0.3740)$ & $(0.2675)$ \\
& $P=0.596$ & $P<0.0001$ & $P<0.0001$ & $P<0.0001$ \\
Phenology effect $(\varphi)$ & 13.4152 & 19.0795 & 3.3057 & 13.9109 \\
& $(3.815)$ & $(8.1443)$ & $(7.6357)$ & $(2.4420)$ \\
& $P<0.0001$ & $P=0.0037$ & $P=0.6835$ & $P<0.0001$ \\
Distance effect $(\beta)^{\mathrm{a}}$ & -0.1503 & 0.0024 & -0.0833 & -0.0497 \\
& $(0.0587)$ & $(0.0235)$ & $(0.0225)$ & $(0.0147)$ \\
& $P=0.0008$ & $P=0.9296$ & $P=0.0003$ & $P=0.0011$ \\
Directionality effect $(\delta)$ & 1.0757 & 0.4046 & 0.4627 & 0.2962 \\
& $(0.6239)$ & $(0.2594)$ & $(0.2288)$ & $(0.1679)$ \\
& $P=0.0252$ & $P=0.0916$ & $P=0.0335$ & $P=0.0654$ \\
Estimates calculated from & main parameters & & \\
Main direction of & 172 & 306 & 358 & 353 \\
pollen influx $\left(\alpha_{0}\right)$ & & & & \\
(degrees from north) & & & & \\
Mean physical & 20.43 & 20.53 & 20.61 & 20.54 \\
distance (m) & & & & \\
Mean effective & 14.75 & 21.28 & 16.52 & 18.54 \\
dispersal distance (m) & & & & \\
$N_{\mathrm{e}}$ & 5.68 & 7.87 & 10.24 & 10.95 \\
$N_{\mathrm{e}} / N(\%)$ & 26.07 & 35.60 & 45.39 & 49.31 \\
\hline
\end{tabular}

${ }^{a}$ Estimates significantly heterogeneous across reproductive phenology classes. 

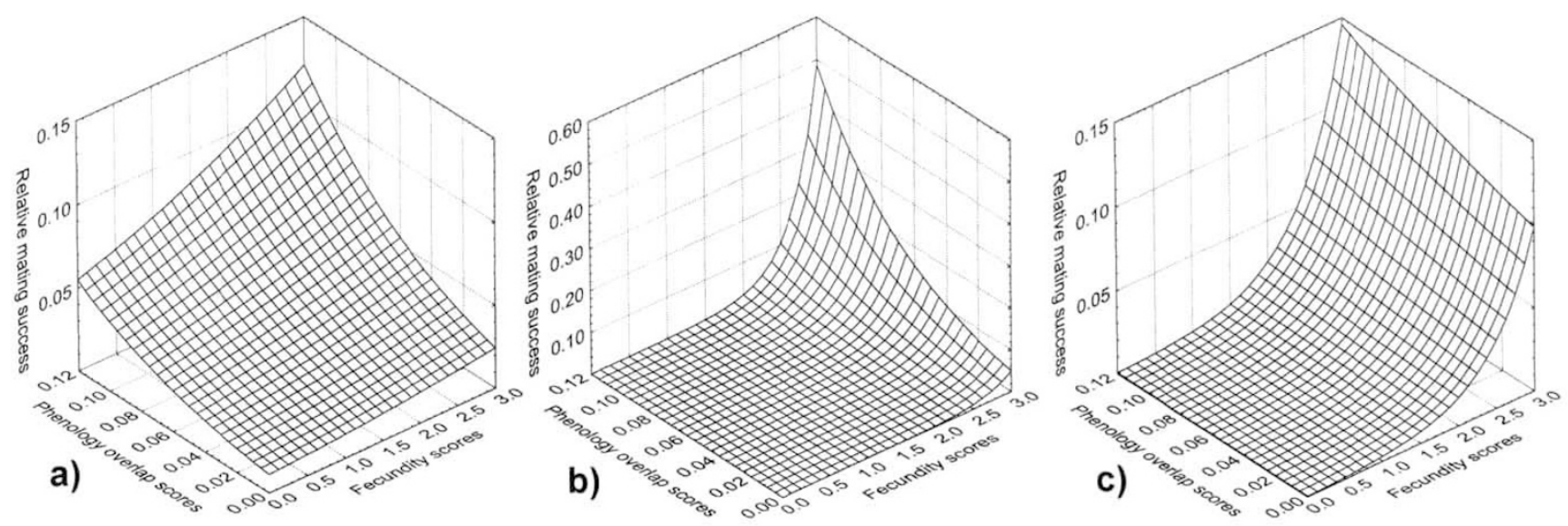

Fig. 1 The joint effects of pollen fecundity and phenological overlap on relative reproductive success $(\hat{\phi})$ of males within neighbourhoods of different phenology groups of Pseudotsuga menziesii (a, early; b, intermediate; c, late), when other effects are ignored. The plots are based on $\phi$ values over all neighbourhoods within each group $(23,36,35$, respectively, for early, intermediate and late) and are specific for the observed distributions of fecundity and phenology overlap scores of male trees in these neighbourhoods.

directionality effect was observed only for the early and late phenology classes.

Differential mating success of individual males results in reduced effective population size $\left(N_{\mathrm{e}}\right)$ of male parents compared to the census population. The effective population size of male trees in the neighbourhood, based on the individual fertilities obtained from eqn (2), was found to be 10.95 individuals for the total population, with each individual having an equal probability of mating with a mother tree. The $N_{\mathrm{e}}$ estimates increased through time from 5.68 in the early, through 7.87 in the intermediate, to 10.24 individuals in the late phenology group (Table 2).

\section{Discussion}

The influence of several environmental (distance and direction) and biological (fecundity and phenology) factors on male reproductive success was
Fig. 2 The effect of distance from mother tree on relative reproductive success $(\hat{\phi})$ of males of Pseudotsuga menziesii within neighbourhoods of different phenology groups when other effects are ignored. The plot is based on $\hat{\phi}$ values over all neighbourhoods within each group and is specific for the observed distribution of distances of male trees in these neighbourhoods.

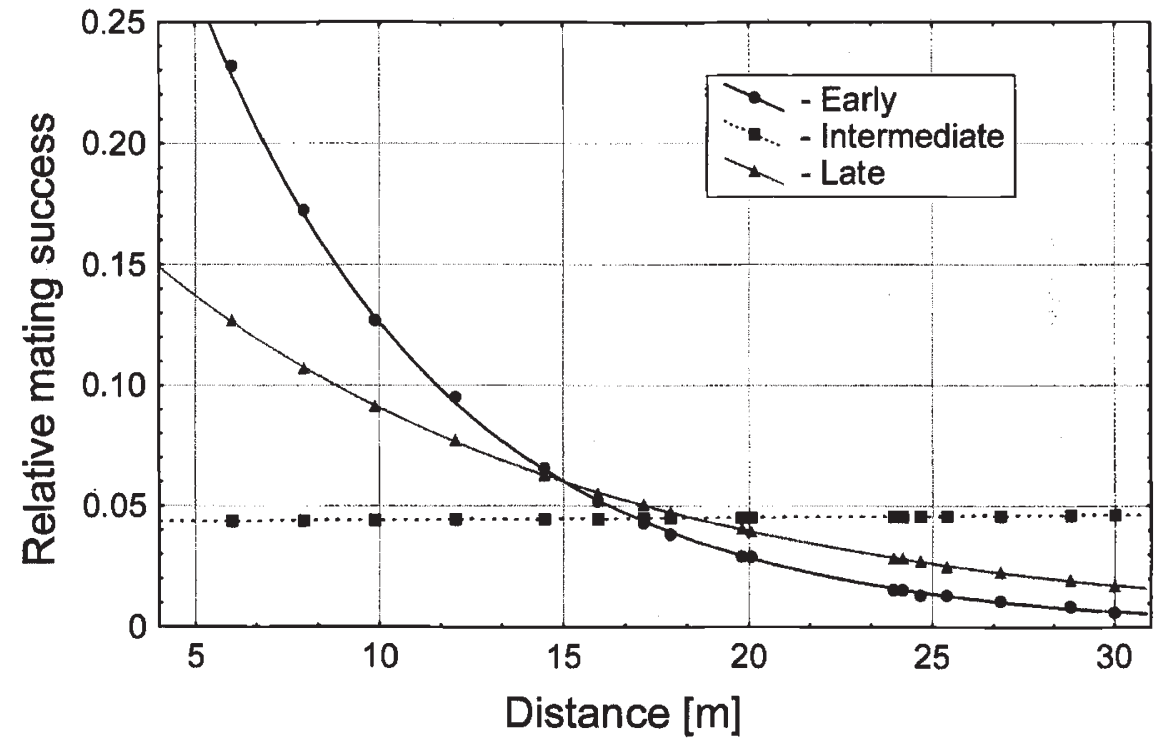




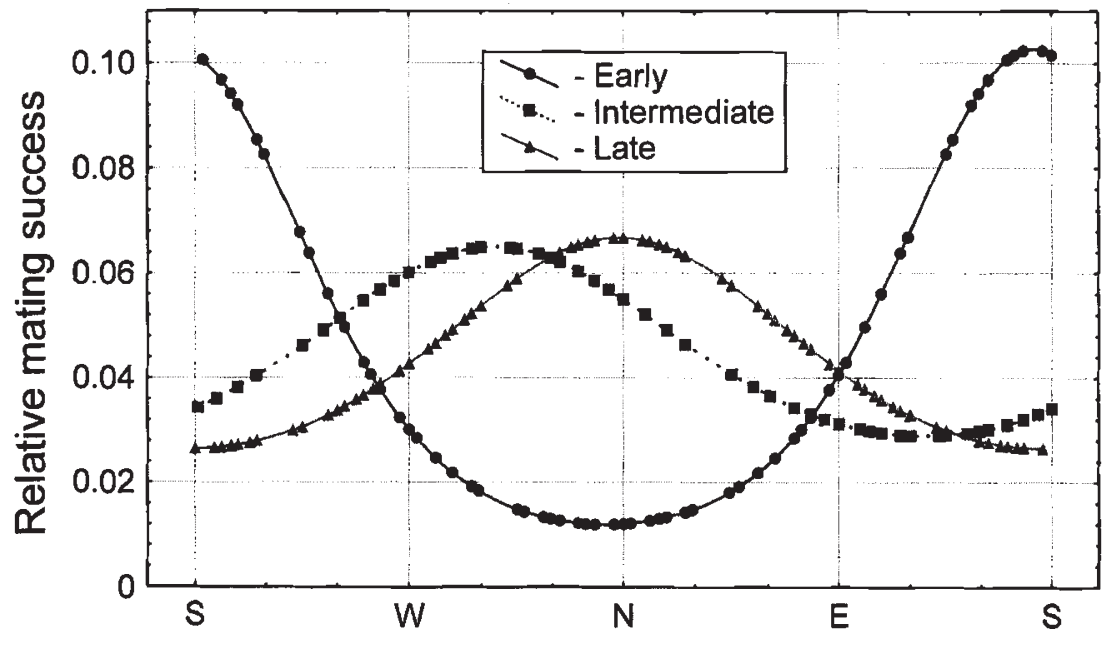

Geographical direction
Fig. 3 Relationship between relative reproductive success $(\hat{\phi})$ of males of Pseudotsuga menziesii within neighbourhoods and their location relative to that of the mother tree (i.e. direction from the mother trees) for three phenology groups when other effects are ignored. The plot is based on $\hat{\phi}$ values over all neighbourhoods within each group and is specific for the observed distribution of relative locations of male trees in these neighbourhoods. expected from many past and recent studies, although the exact relationship was not known. In this study we used genetic analysis for detailed investigations of mating patterns and effective pollen dispersal in a Douglas-fir seed orchard.

The levels of outcrossing estimated in this study were almost identical for the mixed mating (0.963) and the neighbourhood $(0.970 ; t=1-s)$ models. They were generally higher, although similar to the estimates reported in natural and artificial Douglasfir populations (Neale \& Adams, 1985; Ritland \& El-Kassaby, 1985; El-Kassaby et al., 1988).

Phenology is probably the single most important influence on outcrossing patterns in seed orchards (Jonsson et al., 1976; El-Kassaby et al., 1988; Erickson \& Adams, 1989; Wheeler et al., 1993). The lack of flowering phenology overlap among clones may prevent some pairs of clones producing offspring and the reproductive success of males which tend to flower earlier or later than the majority may be substantially reduced. Clonal variation in pollen (or male strobili) production of many coniferous trees is also large (Jonsson et al., 1976; Burczyk \& Chałupka, 1997), which may have further implications for male reproductive success. However, the possibility of clone $\times$ year interaction in pollen fecundity may influence the variation of male reproductive success in consecutive years.

The influence of pollen fecundity on mating success was investigated in a white spruce (Picea abies Voss) seed orchard using a mating model (Schoen \& Stewart, 1986). The male fertility of individual clones varied from 0 to 14.6 per cent and male reproductive success of a pollen parent was significantly related to its pollen production. From Fig. 1 it can be seen that the reproductive success of a single male observed in this study is low when either its fecundity or phenology overlap with a mother tree is small, independent of other factors. In order to be successful, a male tree must produce a large amount of pollen and must be synchronized in flowering with a mother tree.

Despite the absence of pollen contamination from surrounding stands, more than 54 per cent (on average) of fertilizing pollen gametes came from outside the designated neighbourhoods, from males located greater than $30 \mathrm{~m}$ from mother trees. This suggests that mating between distant individuals in the orchard may occur. Consequently, only about 42 per cent of seeds resulted from outcrossing within a neighbourhood. However, the probability of mating between mother trees and potential males within neighbourhoods was decreased with distance, indicating that most of the matings occurred among near-neighbours. This relationship has been previously found based on rare marker analyses (Müller, 1977; Shen et al., 1981; Yazdani et al., 1989). It was also supported by the observation that the majority of pollen released from isolated trees comes to rest within a few tens of metres (DiGiovanni \& Kevan, 1991). Apparently, the distance effect was not significant in two Douglas-fir seed orchards studied using the neighbourhood model (Adams \& Birkes, 1991; Adams et al., 1992a); the authors postulated that the effect of distance was probably obscured by clonal differences in pollen 
fecundity and phenology. Erickson \& Adams (1989) found that the dispersal of rare markers was strongly associated with distance between mating individuals only when floral synchrony among clones was high. In another Douglas-fir seed orchard which was subjected to flower stimulation the distance effect was detected, and was more important in stimulated than in unstimulated orchard blocks (W. T. Adams, J. Burczyk, D. S. Birkes and V. D. Hipkins, unpubl. obs.). Distance appeared to be significant in a natural stand of knobcone pine (Pinus attenuata Lemmon.) (Burczyk et al., 1996).

Patterns of directionality of pollen dispersal, based on genetic marker data, have been studied only in a limited way (Shen et al., 1981; Erickson \& Adams, 1989; Prat, 1995) primarily using a sourceorientated approach (Wheeler et al., 1993). It was generally found that capture of rare marker alleles by female receptor trees was greatest downwind of the male marker (Shen et al., 1981). Prat (1995), applying an elliptical model, indicated that pollen dispersal took place preferentially along rows of trees, but he also suggested a wind effect. The same methods as in this study were used to investigate pollen dispersal in a natural stand of knobcone pine (Burczyk et al., 1996). The mating success was greatest for males located east of mother trees, but it was not related directly to general wind directions.

The method of determining direction of pollen influx presented in this study is efficient only if one prevailing direction exists. This feature probably caused the problems with estimating the prevailing direction for the total population because, during the whole flowering period (17 days), wind patterns (direction and speed) could change several times. Once the different phenology classes were considered separately (each class covered a period of 5-7 days, see Materials and methods) it appeared that the directionality effect was significant for the early and the late phenology groups. The only information about wind patterns during pollination comes from two close meteorological stations (Gourdon and Le Montat) located $14 \mathrm{~km}$ northnorth-east and $27 \mathrm{~km}$ south-south-east from the seed orchard, respectively. The wind speed and direction recorded at $09.00,12.00$ and $15.00 \mathrm{~h}$ indicated that both were changing during the flowering period, but they were mainly consistent between the two meteorological stations (data not shown). Generally, it was found that the direction of pollen dispersal calculated from the model was more or less comparable with the wind patterns observed at the beginning of the flowering period of the given phenology class (data not shown).
Although outcrossing (or selfing) rates were fairly constant across phenology classes, background pollination was continuously decreasing from 0.677 to 0.481 . This could result from an increasing production of pollen within neighbourhoods, as well as from the observed decreasing wind speed during the pollination period. In consecutive phenology groups different factors influenced male reproductive success to different degrees (Table 2). Spatial distribution of males (distance and direction) had no effect in the intermediate class but was very important in the early and the late groups. The fecundity effect appeared to be very significant in the intermediate and the late phenology classes, when most of the clones were already capable of shedding pollen. Phenology was most important in the early reproductive phenology group, whereas it was not significant in the late one. This suggests that at the beginning of flowering, especially when a deficiency of pollen may occur, phenology overlap among mating individuals is a crucial factor determining male reproductive success. Its importance, however, may be decreasing when pollen from many clones becomes available towards the end of the flowering period. These results support the "first-come, firstserved' hypothesis (Owens et al., 1981). In the intermediate class both fecundity and phenology effects, being very significant, probably obscured the influence of distance and directionality (Erickson \& Adams, 1989; Adams \& Birkes, 1991; Adams et al., 1992a).

Although in this study we investigated only the influence of distance, directionality, male fecundity and phenology overlap on male reproductive success, a variety of other factors may also be important. However, regardless of the mechanisms generating male fertility variation, the apparent presence of differential male fertilities is of great importance in forest tree improvement programmes, as well as for genetic conservation purposes. The usual assumptions that the parents of open-pollinated progenies have the same contribution (equal fertility among male parents) may lead to either over- or underestimates of additive genetic variance, which, in turn, causes biases in estimates of heritability, genetic gains and other genetic parameters (Squillace, 1974).

The ability to measure differences in male reproductive success in natural and artificial populations is central to a number of important problems in population genetics and population biology (Smouse \& Meagher, 1994). In this study we found that the neighbourhood model appeared to be very effective in determining different aspects of mating patterns. 
In particular, it allowed several factors influencing male reproductive success to be determined. Because the neighbourhood model approach can incorporate a variety of these factors, it is a promising tool for further studies of mating patterns in plant populations.

\section{Acknowledgements}

We thank CEDAGREF, which is in charge of management of the studied seed orchard, for its help and interest in this study. This research was undertaken while J.B. was a visiting scientist in ENGREF, Nancy, thanks to the fellowship provided by CIES (Centre International d'Etudiants et Stagiaires, France). The final stage of this paper was prepared when J.B. received the award fellowship from the Foundation for Polish Science. This work was supported by the Ministère de la Recherche et de la Technologie (grant no. MRT 90-G-0755).

\section{References}

ADAMS, w. T. 1992. Gene dispersal within forest tree populations. New Forests, 6, 217-240.

ADAMS, W. T. AND BIRKES, D. s. 1989. Mating patterns in seed orchards. In: Proceedings of the 20th Southern Forest Tree Improvement Conference, June 26-30, 1989, pp. 75-86. Charleston, SC.

ADAMS, w. T. AND BIRKES, D. S. 1991. Estimating mating patterns in forest tree populations. In: Fineschi, S., Malvolti, M. E., Cannata, F. and Hattemer, H. H. (eds) Biochemical Markers in the Population Genetics of Forest Trees, pp. 157-172. SPB Academic Publishing, The Hague, Netherlands.

ADAMS, W. T., NEAlE, D. B., DOERKSEN, A. H. AND SMITH, D. B. 1990. Inheritance and linkage of isozyme variants from seed and vegetative bud tissues in coastal Douglas-fir [Pseudotsuga menziesii var. menziesii (Mirb.) Franco]. Silvae Genet., 39, 153-167.

ADAMS, W. T., BIRKES, D. S. AND ERICKSON, v. J. 1992a. Using genetic markers to measure gene flow and pollen dispersal in forest tree seed orchards. In: Wyatt, R. (ed.) Ecology and Evolution of Plant Reproduction, pp. 37-61. Chapman and Hall, New York.

ADAMS, W. T., GRIFFIN, A. R. AND MORAN, G. F. $1992 \mathrm{~b}$. Using paternity analysis to measure effective pollen dispersal in plant populations. Am. Nat., 140, 762-780.

BONNET-MASIMBERT, M. AND WEBBER, S. E. 1995. From flower induction to seed production in forest tree seed orchard. Tree Physiol., 15, 419-426.

BROYLES, S. B. AND WYATT, R. 1991. Effective pollen dispersal in a natural population of Asclepias exaltata: the influence of pollinator behavior, genetic similarity, and mating success. Am. Nat., 138, 1234-1249.
BURCZYK, J. AND CHA£UPKA, w. 1997. Flowering and cone production variability and its effect on parental balance in a Scots pine clonal seed orchard. Ann. Sci. For., 54, 129-144.

BURCZYK, J., ADAMS, W. T. AND BIRKES, D. S. 1993. NEIGHBOR. A computer program for estimating mating patterns in conifer populations from genetic marker data. Release 1. Oregon State University, Oregon. Unpublished. (The program can be obtained from the first author by sending a diskette.)

BURCZYK, J., ADAMS, w. T. AND SHIMIZU, J. Y. 1996. Mating patterns and pollen dispersal in a natural knobcone pine (Pinus attenuata Lemmon.) stand. Heredity, 77, 251-260.

CONKLE, M. T., HODGSKISS, P. D., NUNNALLY, L. B. AND HUNTER, S. C. 1982. Starch Gel Electrophoresis of Conifer Seeds: a Laboratory Manual. USDA Forest Service General Technical Report, PSW-64.

DEVLIN, B., ROEDER, K. AND ELLSTRAND, N. C. 1988. Fractional paternity assignment: theoretical development and comparison to other methods. Theor. Appl. Genet., 76, 369-380.

DEVlin, B., CleGG, J. AND ellstrand, N. C. 1992. The effect of flower production on male reproductive success in wild radish populations. Evolution, 46, 10-30.

DI-GIOVANNI, F. AND KEVAN, P. G. 1991. Factors affecting pollen dynamics and its importance to pollen contamination: a review. Can. J. Forest Res., 21, 1155-1170.

EL-KASSABY, Y. A., RITLAND, K., FASHLER, A. M. K. AND DEVITT, w. J. B. 1988. The role of reproductive phenology upon the mating system of a Douglas-fir seed orchard. Silvae Genet., 37, 76-82.

ERICKSON, V. J. AND ADAMS, w. T. 1989. Mating success in a coastal Douglas-fir seed orchard as affected by distance and floral phenology. Can. J. Forest Res., 19, $1248-1255$.

JONSSON, A., EKBERG, I. AND ERIKSSON, G. 1976. Flowering in a seed orchard of Pinus sylvestris L. Stud. Forest. Suec., 135, 1-38.

LEWANDOWSKI, A. AND MEJNARTOWICZ, L. 1992. Inheritance of formate dehydrogenase in Douglas-fir (Pseudotsuga menziesii (Mirb.) Franco). Genetica Polonica, 33, 295-300.

MÜLleR, G. 1977. Cross-fertilization in a conifer stand inferred from enzyme gene-markers in seeds. Silvae Genet., 26, 223-226.

MUONA, o. 1990. Population genetics in forest tree improvement. In: Brown, A. H. D., Clegg, M. T., Kahler, A. L. and Weir, B. S. (eds) Plant Population Genetics, Breeding, and Genetic Resources, pp. 282-298. Sinauer, Sunderland, MA.

NEALE, D. B. AND ADAMS, w. T. 1985. The mating system in natural and shelterwood stands of Douglas-fir. Theor. Appl. Genet., 71, 201-207.

OWENS, J. N., SIMPSON, S. J. AND MOLDER, M. 1981. The pollination mechanism and the optimum time of pollination in Douglas fir (Pseudotsuga menziesii). Can. J. Forest Res., 11, 36-50. 
PRAT, D. 1995. Mating system in a clonal Douglas-fir (Pseudotsuga menziesii (Mirb.) Franco) seed orchard. II. Effective pollen dispersal. Ann. Sci. For., 52, 213-222.

RAO, C. R. 1973. Linear Statistical Inference and its Applications, 2nd edn. John Wiley \& Sons, New York.

RITLAND, K. AND EL-KASSABY, Y. A. 1985. The nature of inbreeding in a seed orchard of Douglas-fir as shown by an efficient multilocus model. Theor. Appl. Genet., 71, 375-384.

ROEDER, K., DEVLIN, B. AND LINDSAY, B. G. 1989. Application of maximum likelihood methods to population genetic data for the estimation of individual fertilities. Biometrics, 45, 363-379.

SAVOlainen, o. 1991. Pollen contamination in seed orchards. In: Lindgren, D. (ed.) Proceedings of the Meeting of the Nordic Group for Tree Breeding 1991, pp. 6-13. Swedish University of Agricultural Sciences, Department of Forest Genetics and Plant Physiology, Umeå. Rep. 10.

SCHOEN, D. J. AND STEWART, S. C. 1986. Variation in male reproductive investment and male reproductive success in white spruce. Evolution, 40, 1109-1120.

SHEN, H.-H., RUDIN, D. AND LINDGREN, D. 1981. Study of pollination pattern in a Scots pine seed orchard by means of isozyme analysis. Silvae Genet., 30, 7-15.
SMOUSE, P. E. AND MEAGHER, T. R. 1994. Genetic analysis of male reproductive contributions in Chamaelirium luteum (L.) Gray (Liliaceae). Genetics, 136, 313-322.

SNEDECOR, G. W. AND COCHRAN, w. G. 1980. Statistical Methods, 7th edn. Iowa State University Press, Ames, IA.

SNOW, A. A. AND LEWIS, P. O. 1993. Reproductive traits and male fertility in plants: empirical approaches. Ann. Rev. Ecol. Syst., 24, 331-351.

SQuillace, A. E. 1974. Average genetic correlations among offspring from open-pollinated forest trees. Silvae Genet., 23, 149-156.

WHEELER, N. C. AND JECH, K. S. 1992. The use of electrophoretic markers in seed orchard research. New Forests, 6, 311-328.

WHEELER, N. C., ADAMS, w. T. AND HAMRICK, J. L. 1993. Pollen distribution in wind-pollinated seed orchards. In: Bramlett, D. L., Askew, G. R., Blush, T. D., Bridgwater, F. E. and Jett, J. B. (eds) Advances in Pollen Management, pp. 25-31. USDA Forest Service Agricultural Handbook 698.

YAZDANI, R., LINDGREN, D. AND STEWART, S. 1989. Gene dispersion within a population of Pinus sylvestris. Scand. J. Forest Res., 4, 295-306. 